\title{
Factors affecting gestation length in small sized breeds of dogs"
}

\author{
R. H. Vinaykumar*1, R. S. Abhilash², C. Jayakumar ${ }^{3}$, \\ (iD) (iD \\ Amritha Aravind ${ }^{4}$ and V. L. Gleeja ${ }^{5}$ \\ Department of Animal Reproduction, Gynaecology and Obstetrics, \\ College of Veterinary and Animal Sciences, Mannuthy, Thrissur- 680651 , \\ Kerala Veterinary and Animal Sciences University, Kerala, India.
}

Citation: Vinaykumar, R. H., Abhilash, R. S., Jayakumar, C., Amritha, A. and Gleeja, V. L. 2021. Factors affecting gestation length in small sized breeds of dogs. J. Vet. Anim. Sci. 52(4): 335-338 DOI: https://doi.org/10.51966/jvas.2021.52.4.335-338

Received: 08.02.2021

Accepted: 30.03.2021

Published: 15.12.2021

\section{Abstract}

A large variation in the gestation length can be expected when the gestation is calculated from the day of mating to birth. The present study was designed to assess the influence of different factors like litter size, breed, parity and age on gestation length in bitches. A total of 89 small sized bitches of different breeds having different age, parity and body weight, were selected for the study. The mean age, body weight and parity of the animals included in the present study were $3.00 \pm$ 0.15 years ( 1 to 8 years), $9.9 \pm 0.25 \mathrm{Kg}$ (6 to $15 \mathrm{~kg}$ ) and $1.14 \pm 0.10\left(0-4^{\text {th }}\right.$ parity) respectively. The mean gestation lengths observed in different small sized breeds were $60.68 \pm 0.55,59.82 \pm 0.54$, $60.78 \pm 1.74,58.83 \pm 1.35$ and $58.17 \pm 0.74$ in the Pug, Beagle, Dachshund, French Bulldog and the Spitz, respectively. The mean litter size in the study was $4.34 \pm 0.13$ with a range of 2-8. The mean gestational length in animals having $\leq 3$ litter size was $60.83 \pm 0.64$ days and $59.90 \pm 0.43$ days in animals having $>3$ litter size. Age limit of the animals ranged from 1 to 8 years with a mean of $3 \pm 0.15$ years. The mean gestation length in bitches aged $\leq 3$ years was $60.21 \pm 0.23$ days $(n=63)$ and this was $60.15 \pm 0.3(n=26)$ days in bitches in the $>3$ years group. Mean gestational length observed in nulliparous bitches was $60.86 \pm 0.4$ days $(n=29)$, while in multiparous bitches it was $59.90 \pm 0.5$ days $(n=60)$. From the present investigation it could be concluded that no significant difference exists in gestational length between different breeds, litter size, age group and parity.

Keywords: Gestation length, breed, age, parity, litter size

Running title: Factors affecting gestation length in small dogs

"Part of MVSc thesis submitted to Kerala Veterinary and Animal Sciences University, Pookode, Wayanad, Kerala

1. MVSc Scholar

2. Assistant Professor

3. Assistant Professor and Head (i/c)

4. Assistant Professor

5. Assistant Professor and Head (i/c), Department of Statistics

*Corresponding author: vinnu5579@gmail.com, Ph: 9535866603

Copyright: @ 2021 Vinaykumar et al. This is an open access article distributed under the terms of the Creative Commons Attribution 4.0 International License (http://creativecommons.org/licenses/by/4.0/), which permits unrestricted use, distribution, and reproduction in any medium, provided the original author and source are credited. 
Canine gestation length is highly variable when gestation is calculated as the interval from the day of breeding to the day of whelping. Naaktgeboren, 1987 and Concannon et al., 1983 reported that gestational length is expressed as the interval from day of mating or from a single mating to the day of whelping. They also reported that gestation length could vary from 57-72 days (14 days), when calculated from the first day of multiple breeding. Gestational length of canines when calculated from mating to parturition varies from 54-77 days (24 days) in various breeds of dogs. This wide variation in gestation length is observed due to the long period of receptivity, long viability of spermatozoa, variations in onset of oestrus and ovulation and litter size (Okkens et al., 2001; Kutzler et al., 2003). Some authors have reported that litter size, age of the dam, parity and breed have no influence on gestation length, whereas others reported a longer gestation length in smaller litter sizes of either less than 7 or less than 3 puppies (Beccaglia and Luvoni, 2006; Okkens et al., 2001). Compared to Rottweilers (65.6 \pm 1.6 days), German Shepherds (63.2 \pm 1.8 days) had shorter gestation (Mir et al., 2011). Perusal of literature revealed conflicting reports about the 0 influence of different factors on gestation length. In view of above observations, the present study was designed to assess effect of different factors like litter size, age, parity and breed on gestation length

\section{Materials and methods}

A total of 89 small sized bitches of different breeds (Pug, Pomeranian, Spitz, Dachshund, French Bulldog and Beagle) of different ages, parity and body weight, presented to University Veterinary Hospitals, Kokkalai and Mannuthy during the period January 2018 to December 2020 were selected for the study. History regarding age, parity and body weight were recorded. The optimum time for mating was advised based on exfoliative vaginal cytology. Mean age, body weight and parity of the animals included in the present study were $3.00 \pm 0.15$ years ( 1 to 8 years), $9.9 \pm 0.25 \mathrm{Kg}$ (6 to $15 \mathrm{~kg})$ and $1.14 \pm 0.10$ (0-4 ${ }^{\text {th }}$ parity) respectively. Pregnancy diagnosis was carried out by day 30 by trans-abdominal ultrasonography and information regarding the day of whelping and litter size were collected. The length of gestation was defined as the interval between the last day of breeding and the day of whelping. The relationship between different factors like litter size, age, parity and breed on gestation length were analysed by Spearman rank correlation coefficient test using SPSS version 24.

\section{Results and discussion}

The mean gestation length observed in different small sized breeds were $60.68 \pm 0.55$, $59.82 \pm 0.54,60.78 \pm 1.74,58.83 \pm 1.35$ and $58.17 \pm 0.74$ in the Pug, Beagle, Dachshund, French Bulldog and the Spitz, respectively (Table 1). Even though there was a difference of two days in gestation length for the French Bulldog (58.83 \pm 1.35$)$ and the Spitz (58.17 $\pm 0.74)$, when compared to the Pug (60.68 \pm $0.55)$ and the Dachshund (60.78 \pm 1.74$)$, the difference was non-significant $(p \geq 0.05)$. The overall mean gestation length observed in the study was $60.21 \pm 0.36$ days with a range of 53-71 days and similar findings were observed in the study of Holst and Phemister (1974), Concannon et al. (1983) and Okkens (1993). These authors highlighted the inaccuracy of prediction of parturition based on breeding date which is highly variable. The wide variation in the length of gestation may be due to long survivability of canine spermatozoa up to 5-7 days in the female reproductive tract, the long period of receptivity, litter size, variation in the onset of oestrus and ovulation (Concannon et al., 1993).

The mean litter size in the study was $4.34 \pm 0.13$ with a range of $2-8$ (Table 1$)$. The mean gestational length in animals having $\leq 3$ litter size was $60.83 \pm 0.64$ days and $59.90 \pm$ 0.43 days in animals having $>3$ litter size. No significance difference $(p<0.05)$ was observed for gestation length in relation to litter size. This is in accordance with Alonge et al. (2016) who reported no significant difference in gestation length in relation to litter size. However, Mir et al. (2011) reported longer gestation length when the litter size was one or two (65.2 \pm 2.6 days) compared to those litters having 3-9 foetuses $(62.8 \pm 1.9$ days) and 10 or more foetus (62.2 \pm 
Table 1. Influence of different factors like breed, litter size, age and parity on gestation length in different small sized breeds of dogs

\begin{tabular}{|c|l|c|c|}
\hline \multicolumn{2}{|c|}{ Factors } & No. of animals & $\begin{array}{c}\text { Gestation length } \\
\text { (Mean } \pm \text { SE) }\end{array}$ \\
\hline \multirow{3}{*}{ Breed } & Pug & 37 & $60.68 \pm 0.55^{\text {ns }}$ \\
\cline { 2 - 4 } & Beagle & 28 & $59.82 \pm 0.54^{\mathrm{ns}}$ \\
\cline { 2 - 4 } & Dachshund & 9 & $60.78 \pm 1.74^{\mathrm{ns}}$ \\
\cline { 2 - 4 } & French bull dog & 6 & $58.83 \pm 1.35^{\mathrm{ns}}$ \\
\cline { 2 - 4 } & Spitz & 9 & $58.17 \pm 0.74^{\mathrm{ns}}$ \\
\hline \multirow{3}{*}{ Litter size } & Overall & 89 & $60.21 \pm 0.36$ \\
\hline \multirow{2}{*}{ Age } & $\leq 3$ & 30 & $60.83 \pm 0.64$ \\
\cline { 2 - 4 } & $>3$ & 59 & $59.90 \pm 0.43$ \\
\hline & $1-3$ year & 63 & $60.21 \pm 0.23$ \\
\cline { 2 - 4 } & $>3$ year & 26 & $60.15 \pm 0.30$ \\
\hline \multirow{2}{*}{ Parity } & Nulliparous & 29 & $60.86 \pm 0.4$ \\
\cline { 2 - 4 } & Multiparous & 60 & $59.90 \pm 0.5$ \\
\hline
\end{tabular}

Table 2. Correlation between gestation length and factors affecting gestation length

\begin{tabular}{|c|c|c|c|}
\hline Parity & Breed & Age & Litter Size \\
\hline-0.084 & -0.068 & -0.002 & -0.168 \\
\hline
\end{tabular}

1.3 days) in large breeds (German Shepherds, Rottweilers and Golden Retrievers) of dogs.

Age of the animals under the study ranged from 1 to 8 years with a mean of $3 \pm$ 0.15 years. Animals of age from one to three years were categorized in Group I and animals that were more than three years of age were categorized in Group II. The mean gestation length in Group I was 60.21 \pm 0.23 days $(n=63)$ and $60.15 \pm 0.3(n=26)$ days in Group II. No significant difference $(p>0.05)$ was observed between the two groups in relation to gestation length (Table 1) and it can be concluded that age of the dam had no influence on gestational length. This is in accordance with Okkens et al. (2001) and Mir et al. (2011) who studied the relationship between age of the dam and gestation length in large breeds of dogs and reported no significant difference in gestation length of different age grouped bitches.

Parity of animals selected under the study ranged from $0-4$. Animals which were not delivered even once in life time were considered as nulliparous and animals which have whelped once or more than once were categorized as multiparous. Mean gestational length observed in nulliparous bitches was $60.86 \pm 0.4$ days $(n=29)$ while in multiparous it was $59.90 \pm 0.5$ days $(n=60)$. No significant difference was observed in gestational length in relation to parity (Table 1), which was correlated with the findings of Okkens et al. (1993) and Eilts et al. (2005) who found no influence of parity on gestational length. In recent study Mir et al. (2011) found no influence of parity on gestational length in nulliparous $(63.1 \pm 2.2$ days) and multiparous (63.3 \pm 2 days) bitches.

The correlation coefficients were not significant (Table 2) which indicate no evidence for the influence of factors like litter size, parity, age and breed on gestation length. Further, assessment was done by making groups based on these factors.

\section{Conclusion}

The present study was designed to assess the influence of different factors like litter size, breed, parity and age on gestation length 
in bitches. A total of 89 small sized bitches of different breeds having different age, parity and body weight, were selected for the study. The correlation coefficients of different parameters also indicated no evidence for the influence of factors like litter size, parity, age and breed on gestation length. Thus, the study concluded that different factors like breeds, litter size, age and parity did not affect the gestation length in small sized breeds of dogs.

\section{Acknowledgement}

The authors are thankful to the Kerala Veterinary and Animal Sciences University for providing the facilities needed for carrying out the research.

\section{Conflict of interest}

The authors declare that they have no conflict of interest.

\section{Reference}

Alonge, S., Beccaglia, M., Melandri, M. and Luvoni, G.C.2016. Prediction of whelping date in large and giant canine breeds by ultrasonography foetal biometry. J. Small Anim. Pract. 57: 479-483.

Beccaglia, M. and Luvoni, G.C. 2006. Comparison of the accuracy of two ultrasonographic measurements in predicting the parturition date in the bitch. J. Small Anim. Pract. 47: 670-3.

Concannon, P.W., Stevenwhaley, B.S., Lein, D. and Richard Wissler, B.S. 1983. Canine gestation length: Variation related to time of mating and fertile life of sperm. Am. J. Vet. Res. 44: 1819-1821.
Eilts, B.E., Davidson, A.P., Hosgood, G., Paccamonti, D.L. and Baker, D.G. 2005. Factors affecting gestation duration in the bitch. Theriogenology. 64: 242-251.

Holst P.A. and Phemister, R.D. 1974. Onset of diestrus in the Beagle bitch: definition and significance. Am. J. Vet. Res. 35: 401-406.

Kutzler, M.A., Mohammed, H.O., Lamb, S.V. and Meyers-Wallen, V.N. 2003. Accuracy of canine parturition date predictionfrom the initial rise in preovulatory progesterone concentration. Theriogenology. 60: 1187-1196.

Kutzler, M.A., Yeager, A.E., Mohammed, H.O. and Meyers-Wallen, V.N. 2003. Accuracy of canine parturition date prediction using fetal measurements obtained by ultrasonography. Theriogenology. 60: 1309-1317.

Mir, F., Billault, C., Fontaine, E., Sendra, J. and Fontbonne, A. 2011. Estimated pregnancy length from ovulation to parturition in the bitch and its influencing factors: a retrospective study in 162 pregnancies. Reprod. Dom. Anim. 46: 994-998.

Naaktgeboren, C. 1987. De geboorte van de hond en zijn Wilde verwanten. ( $\left.3^{\text {rd }} \mathrm{Ed}\right)$. Naarden, the Netherlands, Strengholt, $31 \mathrm{p}$.

Okkens, A.C., Teunissen, J.M., Van Osch, W., Van Den Brom, W.E., Dieleman, S.J. and Kooistra, H.S. 2001. Influence of litter size and breed on the duration of gestation in dogs. J. Reprod. Fert. Suppl. 193-197. 